
Vol. 2, No. 2, 2012

\section{Discourse of Leader in an} Academic Setting: A Critical Discourse Analysis of Email Messages

\section{Prof. Maya Khemlani David \\ Prof. Francisco Perlas Dumanig}




\title{
Discourse of Leader in an Academic Setting: A Critical Discourse Analysis of Email Messages
}

\begin{abstract}
Emails have become a common tool when communicating to employees in the workplace because this medium of communication saves time and effort. It is a faster mode of communication and information can be delivered in just a few seconds. To some extent sending emails in the workplace has become a norm. Despite the casual nature of emails it has become a tool where leaders try to assert their power and place in an organization. It is therefore the focus of this paper to examine the discourse of an academic leader through emails. This paper will examine the micro and macro level of leadership discourse. To analyze the data, Fairclough's (1993) framework which includes the analysis of textual practice, discourse practice, and social practice will be used. In analyzing the discourse at the micro level, the paper will examine the textual practice which includes vocabulary, grammar, and text structure. In addition, genre and style of text and social practice will also be analyzed.
\end{abstract}

Keywords: critical discourse analysis, communication, academic leaders, emails

\section{Introduction}

The emergence of information technology in the 21st century has brought a number of changes in the mode of communication. Paperless communications like emails, blogs, and online chatting have become popular and available even to ordinary people. In fact, the use of emails nowadays has become a widely preferred mode of communication as compared to the traditional forms of communication. Today, sending messages through emails facilitates instantaneity, and accelerates work as the message will be received immediately by the receiver. Consequently, this mode of communication has been practiced in most offices so as to facilitate faster information.

To examine the discourses of leaders in academic setting, it is essential to discuss the concepts of Computer-Mediated Communication (CMC), leadership in academic settings, language and identity, and Critical Discourse Analysis (CDA).

\section{Computer Mediated Communication (CMC)}

Online and mobile communication through the web, email, chat, and virtual worlds have raised some questions about language change and the impact of emerging technologies on the linguistic and orthographic dimensions of computer-mediated communication (CMC), the shared rules for achieving linguistic competence in the media, and the long-term effects of CMC (Meyer, 2009). It has to be noted that Computer-mediated communication (CMC) may refer to any communicative transaction that occurs through the use of two or more networked computers and has been traditionally referred to communication that occurs via computer-mediated formats e.g. 
instant messages, e-mails, chat rooms (McQuail, 2005). CMC has also been applied to other forms of text-based interaction such as text messaging. In addition, there have been many studies conducted related to $\mathrm{CMC}$ which focus more on the social effects of computer-supported communication technologies (Thurlow, Lengel, \& Tomic, 2004). The emergence of these studies conducted on $\mathrm{CMC}$ reflects its relevance and importance in modern society.

CMC has contributed much to modern communication. In fact, according to Walther, (1996) and Alther \& Burgoon (1992) CMC helps in managing interpersonal interaction, forming impressions and maintaining relationships. With the continuous development of CMC in this highly computerized world, it is appropriate to say that $\mathrm{CMC}$ has become embedded in our everyday life. The frequency of use of CMC has resulted in research like which focuses on the use of paralinguistic features as emoticons (Haythornthwaite and Wellman,2002) pragmatic rules such as turn-taking (Garcia, \& Jacobs 1999); sequential analysis and organization of talk ( Herring, 1999) and various sociolects, styles, registers or sets of terminology specific to these environments (Markman,2006 and Leet,1980). Herring (2004) explains that the study of language in these contexts is typically based on text-based forms of CMC, and is sometimes referred to as "computer-mediated discourse analysis".

In the 21st century, it is evident that the use of computers is a widely preferred mode of communication. McQuail (2005) explains that CMC is able to overcome physical and social limitations of other forms of communication and therefore permits the interaction of people who are not physically sharing the same space. Due to the absence of face to face communication, the construction of multiple identities and images has become common. Nowadays, CMC is also widely used as a mode of communication in the workplace. The way leaders project themselves is reflected through their linguistic and non-linguistic choices in the e-mails they send to their subordinates.

\section{Leadership in an Academic Setting}

It is believed that dominant discourses about leadership shape an individual's beliefs of leadership (Allan, Gordon \& Iverson, 2006). The belief that a leader must be tough, strong, powerful and authoritative may perhaps influence the leaders and subordinates' concept about leadership. A leader can be described as a person who is in-charge of or controls a country, organizations, teams, etc. (Longman dictionary, 1999). In addition, a leader can be described by the 3 P's i.e. as a Person who is committed and influences People to achieve a Purpose. Below is an illustration of this. 


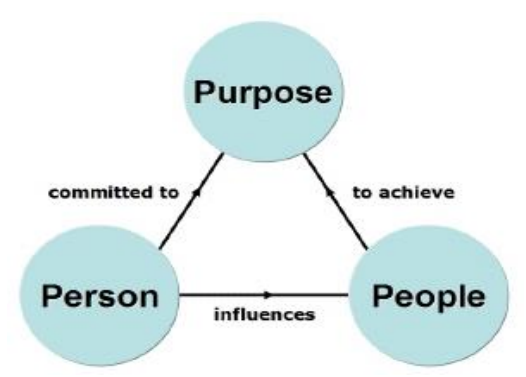

Source: www.vtaide.com/gleanings/leadership

The discourses they use affect the way leaders lead a group or organization. Allan and colleagues (2006) explain that discourses of leaders help in constructing images of leaders. Allan and colleagues (2006) explain that there are four common discourses that shape images of leadership within academia such as autonomy, gender and masculinity, professionalism, and relatedness. The discourse of autonomy shapes an image of the leader as an individual who is uniquely qualified, competent, and morally principled and acts as a "solo leader" (Allan \& colleagues, 2006: 48). The discourses of gender and masculinity form individuals" "expectations of what is considered acceptable behavior for women and men in a given context." The discourse of masculinity positions masculine traits as "taken for granted desired behaviors." The discourse of professionalism forms the belief that individuals are enhanced through the various means which allow for professional/career (Allan \& colleague, 2006: 50). Professional advancement of the leader is seen as more important than helping the collective. The discourse of relatedness positions a leader as one who assists others for the common good of the community.

Leadership requires certain characteristics that would enhance the ability of a leader to lead a group or organization. Such characteristics are believed to be constructed by individual leaders to demonstrate their capabilities and expertise in leading and are revealed through their discourses and language choice. It is believed that people are continually constructing and reconstructing reality through the use of language and the actions taken as a result (Gee, 2005). Language in some ways has a magical property i.e. when we speak or write; we design what we say in order to fit the situation in which we are communicating. Language helps individuals to make sense of their world and enables individuals to construct their actions and understanding within the world. In much the same way that language creates and is created, it is used to signal or construct the identity of the speaker.

\section{Language and Identity}

One's identity can be individually or institutionally constructed and this is usually revealed by a speaker's manner of using the language. Identity is not only constructed individually by a speaker through names, naming practices, and rituals but group identity representation is also constructed (Thomas et.al, 2004). The speaker's identity represents the speech community or 
groups that he or she belongs to. Such identity manifests itself due to linguistic variations that include discourse norms, stylistic variation and even language choice.

Identity has to be enacted and performed in order to be socially salient (Blommaert, 2005). This means that in order to establish an identity, it has to be recognized first by others. This recognition comes from our discourses. However, identity whether on an individual, social or institutional level is something that is constantly being built and negotiated throughout our lives in our interaction with others (Thornborrow, 2004). This means that every time people interact with others either face to face or CMC they are frequently negotiating their identities. Speakers may therefore be creating multiple identities in one speech event because every speaker is concerned with how others may perceive him or her (Goffman, 2007). In short the emphasis on identities is not essentially given but is actively produced through deliberate, strategic manipulation or out-of-awareness practices (Kroskrity, 2000) through our discourses.

An important aspect when studying the construction of identity is a speaker's speech community, which contributes in establishing the speaker's identity. The term speech community is defined as the shared dimension related to the ways in which members of the group use, value, or interpret language. (Saville-Troike, 2003). A speaker's speech community becomes recognizable through a speaker's use of lexical items and manner of speaking. Therefore, group and individual identity can be established within the speech community membership of a speaker.

\section{Critical Discourse Analysis}

In exploring the discourse of leader/s and how the leadership identity is constructed, it is essential to use Critical Discourse Analysis (CDA) as an approach in analyzing the discourse. CDA is a study of discourse which views "language as a form of social practice", and aims to uncover power and dominance as well as inequalities within society and on how it is produced through text and talk" (Fairclough, 1997). It also discovers the relation of language and power as a form of spoken discourse which is a manifestation where the relations of power is evidently exercised and enacted (Fairclough, 1989).

In analyzing discourse, Huckin (1997) recommends the sort of perspective that needs to be addressed in the analysis like the genre, foregrounding, backgrounding, tone of text and register. Foregrounding is used if the text emphasizes a clear and specific issue while backgrounding is used when the text tries to de-emphasize or minimize certain issues (Huckin, 1997). Examining what has been fore-grounded and back-grounded in the text may provide useful analysis of the text to clearly understand the message of the speaker. In addition, the tone of the text can also be an important tool to analyze the discourse because it informs the emphasis made. The tone of the text is specifically used in order to convey the degree of certainty and authority (Huckin, 1997). 
For instance, the use of modals like "can, may, will and might" may further enhance the message.

\section{Methodology}

This paper examined 20 emails sent by a female leader to her subordinates in an academic setting during her two year tenure with a local university. The emails were analyzed using Fairclough's (1993) framework which includes the analysis of textual practice, discourse practice and social practice. The emails were analyzed at two levels of analysis: macro and micro levels. The macro level analysis includes the genre and style of the text and focuses on the discourse practice. On the other hand, the micro level analysis examines the textual practice which includes the vocabulary, grammar and text structure.

\section{Analysis}

\section{Genre}

It is evident that email has become the medium of communication of academic leaders when communicating with their subordinates. The study shows that email messages follow the usual genre of writing an email. The findings reveal that the use of a modified form of a letter where the basic parts of a letter like the greetings, body, complementary close, and signature etc. are present. However the closing statement appears informal. The leader's way of ending the message is by providing good wishes like "have a good week or weekend" and this is used as the complementary close. Such informality makes the email more personal in tone. Such a style of writing may create a more collaborative response from the receiver.

\section{Foregrounding}

The 20 email messages collected of one academic leader reveal that the achievements and the benefits that the university provides are constantly fore-grounded. The emphasis on the achievements and benefits of the university may provide employees a better image as it gives them an impression that they are working in one of the better universities. The staff may consequently develop a positive attitude towards the university and have fewer questions on the policies made and implemented. Such strategies minimize negative attitudes of staff and encourage people to perform better because of the feeling that they are working in a university that has achieved much and provides many benefits. This could also be a means of encouraging staff as such foregrounding projects the high standard of the university.

At the same time, projecting such an image has an implication on the leader's own performance. It signifies that as a leader she has done much to achieve these targets and benefits. In other words, whilst foregrounding an image of a successful university the leader creates an image of a successful leader. 
Such foregrounding is evident in the selected email messages:

"Our university is the only university from the region to have a speaking slot."

"Getting and international or external award would contribute to the image and standing of the university."

"We have an opportunity to introduce our university to foreign academic community."

The fore-grounded messages can be illustrated as follows.

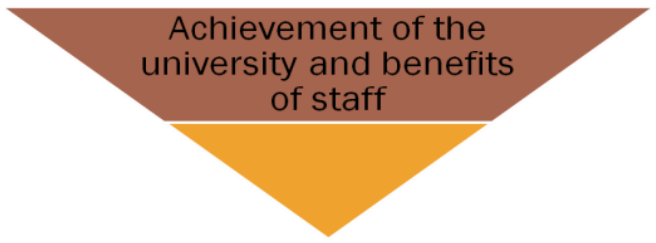

\section{Backgrounding}

Although the achievements and benefits of the university have been fore-grounded in the email messages, it is also evident that the leader did not emphasize the university's failure, and unsuccessful plans and activities. These issues were not mentioned in the email messages. This means that failures and unsuccessful plans were back-grounded in emails. Not emphasizing the failures and projecting only successes help in creating an identity or image of a leader as successful and effective. Such backgrounding minimized the failures or lack of achievements and the foregrounding of the success stories resulted in many positive attributes being attributed to the leader.

In the email messages, the leader mentioned the following messages but no elaboration was made. For instance the leader says, "I don't see why we should deprive our people from keeping their international grants." and "They found a few non-compliance of the university." The speaker back-grounded the international grants and non-compliance of the university in order to keep such issues from possible questioning.

"I don't see why we should deprive our people from keeping their international grants."

"No one will believe us unless we are certified by an independent party that we have the quality."

"They found a few non-compliance of the university." 
"Maybe we should do some self-examination on our readiness for change."

The back-grounded messages presuppose that the university is limiting the international grants, does not comply to certain standards and needs to be certified by an independent party in measuring its quality. These negative implications have not been fore-grounded so as to keep the good image of the university

\section{Power and authority in leadership discourse}

\section{a. The use of pronoun "I" to signal power and authority}

The emails show that power and authority are emphasized by the leader through the use of the pronoun "I". Such a use of this pronoun indicates authority and power which is evident in the following texts:

"I am going to revisit whatever rules that impose such restriction......"

"I stated that logically if the country wants to support one university..."

"I will always deny any suggestion..."

"I will not tolerate any bad-mouthing..."

The occurrence of "I" in the discourse shows that the leader has the power and authority to control the organization. For instance, saying "I am going to revisit whatever rules that impose such restriction.....", "I will not tolerate any badmouthing..." indicates that the leader has the power and authority to impose any policy. Constructing this kind of image may perhaps project a strong yet egocentric leader.

However, it must be noted as well as signifying power in leadership discourse, it is sometimes necessary to project an image of solidarity.

\section{b. The use of pronoun "I" and "We" to show solidarity}

The use of pronouns "I" and "we" also help in establishing solidarity between the leader and her subordinates. In the emails analyzed, the use of "I" and "we" create solidarity between the leader and the subordinates and this is evident in the following extracts:

"I reply to your email myself..."

"I would like to thank each and every colleague..." 
"I wish you all the best..."

"I'm sure most of you would not differ from me..."

“...we could do it."

"We all have been there."

The leader in this academic setting tries to create solidarity with the subordinates to achieve the main objective of the university. The use of "I" and "we" are explicitly used in email communication to create oneness of purpose and solidarity among the members of the organization so as to achieve the objectives/s of the organization.

\section{c. The use of "we, us and our" to signal a communal responsibility}

In the emails analyzed, it shows that the leader shows a communal responsibility to all members of the organization. The leader wants everyone to have the same common goals so as to achieve them. Therefore the use of lexical items like "we, us, and ours" indicate that the speaker tries to get others involved. Such use of pronouns is evident in the emails analyzed.

Examples

"We have some super duper academicians..."

"We also need to plant trees on the slopes..."

"These practices will help us in the peer review category..."

“....we can do it..."

“...came to conduct a sample audit on us..."

\section{Directness of speech: Leadership identity}

The directness of speech signifies power and is a marker of the discourse of a leader. Such directness is evident in the sentence structure of the message.

\section{a. Syntactic structure}

The use of active voice is common. Using the active voice projects an image that the leader has the power and authority as a leader. This also indicates the directness of the speaker in her statements. 
Examples:

"We need to have our scientists speak to them..."

"We have to do something to preserve and beautify ..."

"All of us have a role to play in explaining ..."

"I will tell you more next week of some of the opportunities..."

"I urge all of you to try to and present papers..."

"For your information, the peer review carries $40 \%$ weight age..."

"Your enthusiasm, commitment and support touched me..."

The directness of the message is evident in the grammatical structure. This is perhaps necessary to put the message across clearly to the receiver. The directness of the message also constructs an image of being strong and focused on the goal. This is evident when the leader said

"I urge all of you to try to and present papers...",

"We have to do something to preserve and beautify ...",

"We need to have our scientists speak to them...".

It is clear from the messages that there is power, authority, strong disposition, and the focus is on achieving the goals set.

The use of active voice results in a short and direct message. Being direct is sometimes necessary so as to prevent misunderstanding. Modals like "will, must, should, can" ensure clarity. At times the authority in tone is mitigated when the speaker uses certain models like "may, might, would" to soften the message. In the emails analyzed, it is evident that the use of some modals indicates politeness and less assertive messages. Below mentioned are the models found in the emails:

Examples:

"All of you will try to do just that..."

"We will let you know how much we collected..."

"The committee will judge the quality of the project." 
"All of you should be extremely be proud..."

"It must happen as an evolution if it is to be sustained."

"I'm sure that most of you would not differ from me."

"I stated logically....it should be..."

The use of modals, "will, should, must, would" help to enhance the power and authority of the speaker. "It must happen as an evolution if it is to be sustained." and "I stated logically...it should be..." indicates directness. Apart from using active voice, the presence of the modals "must and should" result in unmitigated directives.

\section{Conclusion}

The use of email as a mode of communication of leaders in an academic setting provides useful information as to how leaders construct their identity as leaders. As email communication is not face to face, the message must project an image and identity of a leader. This is revealed through the linguistic choices of the leader.

\section{References}

1. Blommart, J. (2005) Discourse: Key topics in sociolinguistics. Cambridge: Cambridge University Press.

2. Haythornthwaite, C. and Wellman, B. (2002). The Internet in everyday life: An introduction. In B. Wellman and C. Haythornthwaite (Eds.), The Internet in Everyday Life (pp. 3-41). Oxford: Blackwell.

3. Garcia, A. C., \& Jacobs, J. B. (1999). The eyes of the beholder: Understanding the turntaking system in quasi-synchronous computer-mediated communication. Research on Language \& Social Interaction, 32, 337-367.

4. Herring, S. (1999). Interactional coherence in CMC. Journal of Computer-Mediated Communication, 4(4).http://jcmc.indiana.edu/vol4/issue4/herring.html

5. Herring, S. C. (2004). Computer-mediated discourse analysis: An approach to researching online behavior. In: S. A. Barab, R. Kling, and J. H. Gray (Eds.), Designing for Virtual Communities in the Service of Learning (pp. 338-376). New York: Cambridge University Press.

6. Kroskity, Paul. (2000). Identity. Journal of Linguistic Anthropology, 9 (1-2), 111-114. 
7. Markman, K. M. (2006). Computer-mediated conversation: The organization of talk in chat-based virtual team meetings. Dissertation Abstracts International, 67 (12A), 4388. (UMI No. 3244348)

8. McQuail, Denis. (2005). Mcquail's Mass Communication Theory. 5th ed. London: SAGE Publications.

9. Meyer, C. (2009). Evolutions in email style and usage. Science and Technology for Humanity (TIC-STH), 2009 IEEE Toronto International Conference. 8 April 2010.

10. McQuail, Denis. (2005). Mcquail's Mass Communication Theory. 5th ed. London: SAGE Publications.

11. Thomas, L. et.al (2004). Language, society and power 2nd ed. London: Routledge.

12. Thornborrow, Joanna (2004). Language and identity. Language Society and Power.

13. Thurlow, C., Lengel, L. \& Tomic, A. (2004). Computer mediated communication: Social interaction and the internet. London: Sage.

14. Walther, J. B. (1996). Computer-mediated communication: Impersonal, interpersonal, and hyperpersonal interaction. Communication Research, 23, 3-43.

15. Walther, J. B., \& Burgoon, J. K. (1992). Relational communication in computer-mediated interaction. Human Communication Research, 19, 50-88.

16. issues are discussed but that racist sentiments in multiracial, multilingual Malaysia are not fuelled by irresponsible MPs.

\section{- END -}




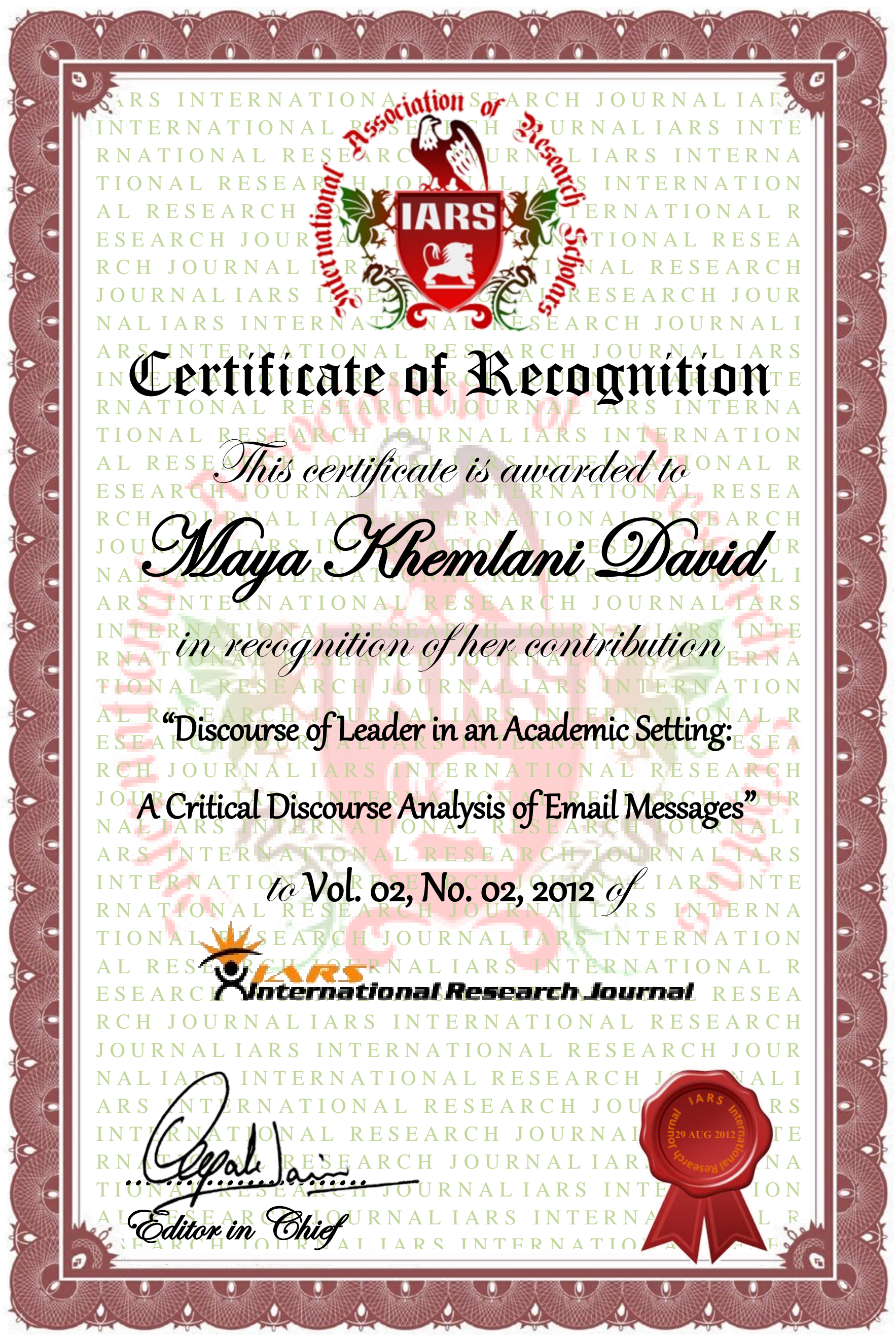

